\title{
Experimental investigation of properties of GFRP foam cored sandwich joints
}

\author{
Jana Gulanová ${ }^{1, *}$, Matúš Margetin ${ }^{1}$, Papa-Birame Gning ${ }^{2}$, Andrej Chríbik ${ }^{1}$ \\ ${ }^{1}$ Faculty of Mechanical Engineering, Slovak University of Technology, Bratislava, Slovakia \\ ${ }^{2}$ Institute of Automotive and Transport Engineering, Université Bourgogne Franche-Comté, Nevers, \\ France
}

\begin{abstract}
Presented paper focuses on intermediate outcomes of the bilateral project between the Faculty of Mechanical Engineering, STU in Bratislava, Slovakia and the Institute of Automotive and Transport Engineering, UBFC in Nevers, France. Thus, mechanical properties and behaviour of glass fibre reinforced polymer composite foam cored sandwich panels joints were researched to estimate the best possible joint technology. Three-point bending and four-point bending were used to evaluate flexure strength and static force-flexure curve. Based on such testing, one specific joint composition was chosen to be broadly investigated. Finally, chosen type of joint panels was tested under four-point cyclic loading to obtain its fatigue properties.
\end{abstract}

Keywords: bending, fatigue, sandwich.

\section{Nomenclature}

$F_{\max } \quad$ - maximal force during loading cycle

$F_{u} \quad$ - ultimate force that specimen type can survive

$\%_{F u}$ - ratio between $\mathrm{F}_{\max }$ and $\mathrm{F}_{\mathrm{u}}$

$F_{m} \quad$ - mean value of force loading cycle

$F_{n f} \quad$ - force corresponding to given number of cycle to failure

$\delta_{m} \quad-\quad$ mean value of flexure cycle

$N_{f} \quad$ - number of cycle to failure

$K \quad$ - fatigue strength coefficient

$B \quad$ - fatigue strength exponent

$R L \quad$ - regress line

$U P I$ - upper predictive interval

$L P I$ - lower predictive interval

$U C I$ - upper confidence interval

$L C I$ - lower confidence interval

$R \quad$ - loading cycle ratio of symmetry

\footnotetext{
* Corresponding author: jana.gulanova@stuba.sk

Reviewers: Juraj Gerlici, František Nový
} 


\section{Introduction and experiment pre-processing}

Presented project was partially focused on an optimal selection of sandwich composition and possible joining of sandwich panels to build specific assemblies within automotive industry. Mechanical validation is complicated and any case of loading analysis needs to be performed as a nonlinear task. In $[2,4]$ authors focus on specific properties of different sandwich structure or joints comparison. But generally, there is a lack of such research dealing with selection and comparison of different permanent joints used within sandwich structures. Such a joint might be useful enabling series production of sandwich beams, which would be possible to be connected to build complex geometry and structures. Possible application here might be a carriage body of trucks or a floor of any kind of vehicle. Similar structures are known to be used in space industry, but here it is without any published research outcomes.

\subsection{Technology - fabrication process}

Sandwich material panel is made of top layers called skin which is sandwiching a core. For the presented project, skin was made of glass fibre reinforced epoxy composite consisting of 8 layers of prepreg cloths. There was used a special PVC foam, which was glued to skins by using epoxy adhesive film. Layer composition is shown in Fig. 1.

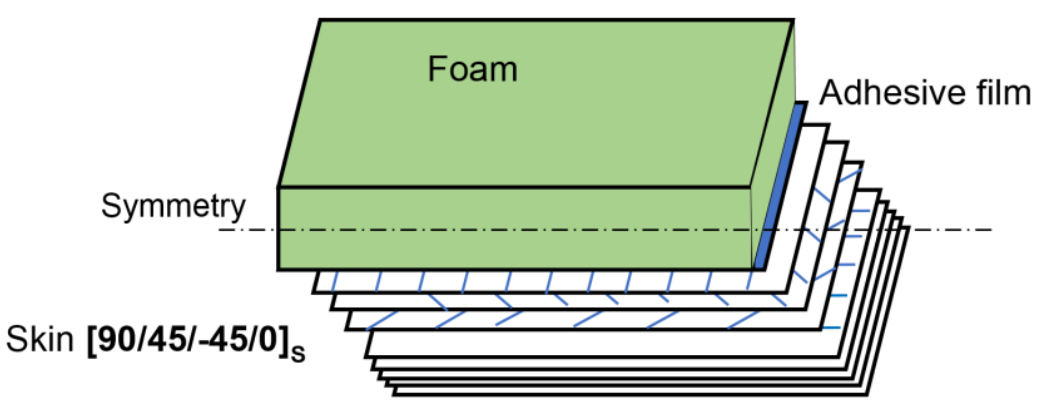

Fig. 1. Layer composition used for the monolith specimen

Fabrication process might be different for real components and structures, there is described panel fabrication process in following sentences. Cloth of prepreg is cut into specific rectangles. Without any glue, eight cloths are placed adhering specific position on each other. Then there is applied a thin film of epoxy glue and skin is stuck together with foam. Prepared sandwich is placed in vacuum bag to an oven and tempered to final form. Fabrication process varies with different joint composition. In Fig. 2, there are shown various joints, which were tested under static loading. For further research, there was chosen aluminium insert of $50 \mathrm{~mm}$ width as joining element. 


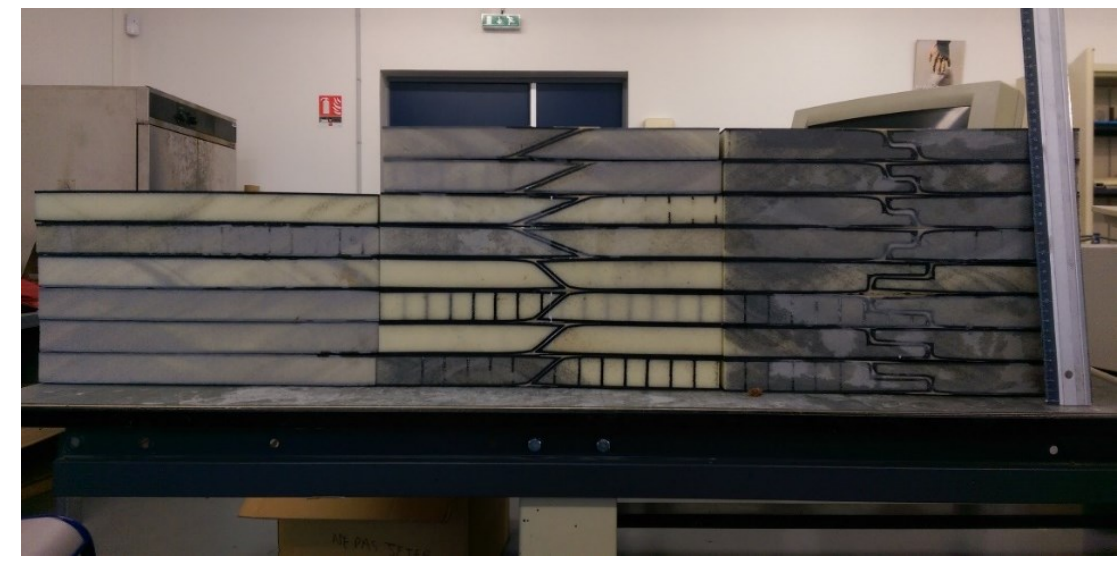

Fig. 2. Various joint structures used for static testing - left column monolith, centre column slope and right column step

\subsection{Testing procedure}

In following subsections, there will be described results of static testing and fatigues testing. Firstly, specimen was tested using static three-point bending and four-point bending to find out the best joining composition. Later, there was done fatigue testing using fourpoint bending. Fatigue tests were performed on monolith structure and $50 \mathrm{~mm}$ width aluminium insert as well. Finally, results of fatigue behaviour are described.

\subsubsection{Quasi-static}

For the purpose of mechanical verification, there were investigated normal stress, displacement and stiffness of specimens fabricated using three kinds of joint and compared to monolith specimens within the same parameters. Such a study is shown in Fig. 3. There are 6 different benches of specimens, M30 as step of size 30mm, M60 as step of 60mmsize, B20 as slope of $20^{\circ}, \mathrm{B} 40$ as slope of $40^{\circ}$, I25 as aluminium insert of $25 \mathrm{~mm}$ size and finally I50 as aluminium insert of $50 \mathrm{~mm}$ size. In Fig. 3, there is shown scattering in comparison to monolith specimen testing. Static mechanical properties are not described more broadly within presented paper, since the main goal was to focus on fatigue behaviour of chosen joint structure.

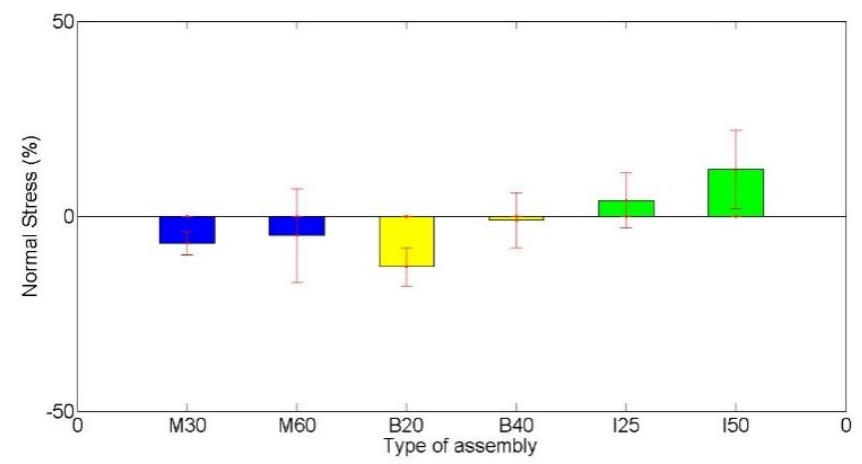



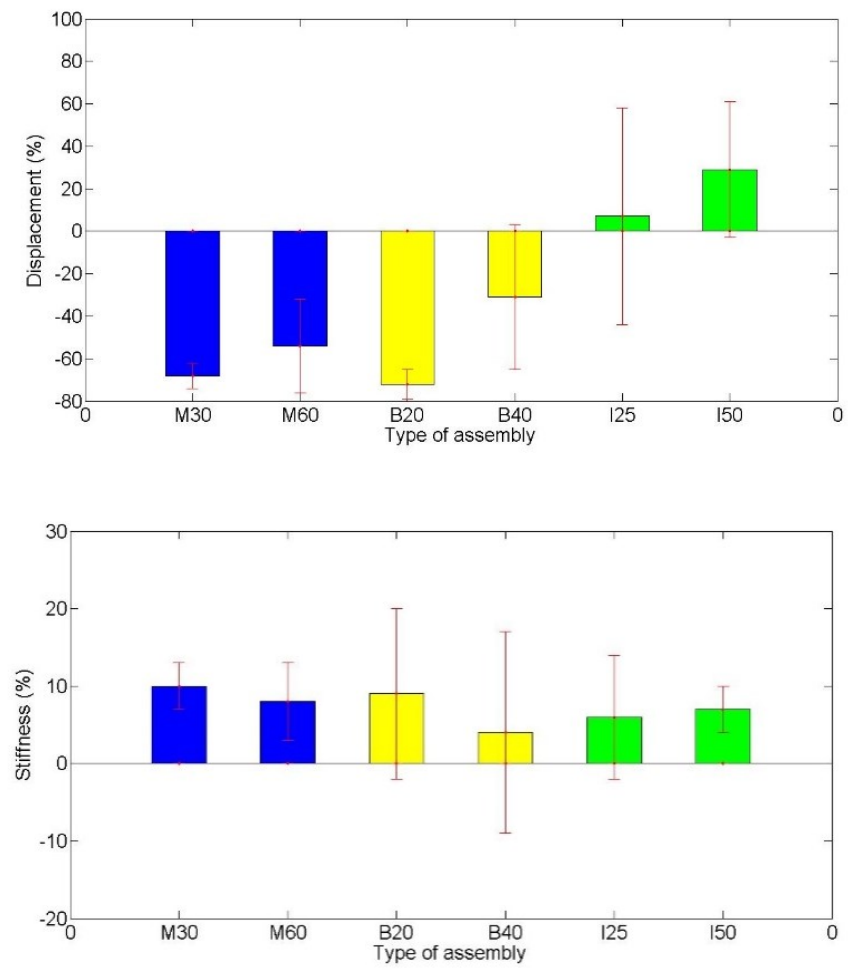

Fig. 3. Scattering in comparison to monolith specimen testing for 6 various joint structures

\subsubsection{Fatigue}

In order to investigate fatigue behaviour of composite sandwich structure, an experiment was conducted in which experimental specimens were tested at different levels of fourpoint bending loading. Experiment was carried out in the Strength and Elasticity Laboratory of the Faculty of Mechanical Engineering STU, using experimental stand Inova EDYZ testing system with maximal capacity of $200 \mathrm{kN}$. Based on results from static testing, two sets of experimental specimens were manufactured, the monolith type specimen and the insert type specimen, as can be seen in Fig. 4.

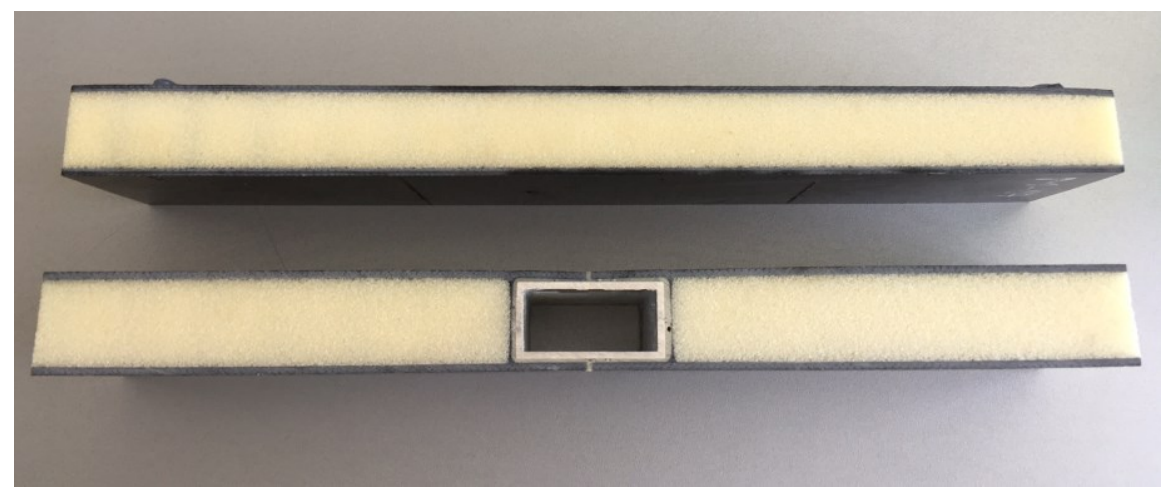

Fig. 4. Testing specimens: monolith - top; insert - bottom 
The deflection of tested specimens has been measured using induction sensor placed in servo hydraulic valve and the loading force has been sensed using load cell mounted in crossbar of testing stand. To achieve four-point bending loading condition, specimens have been placed in mounting device shown in Fig. 5.

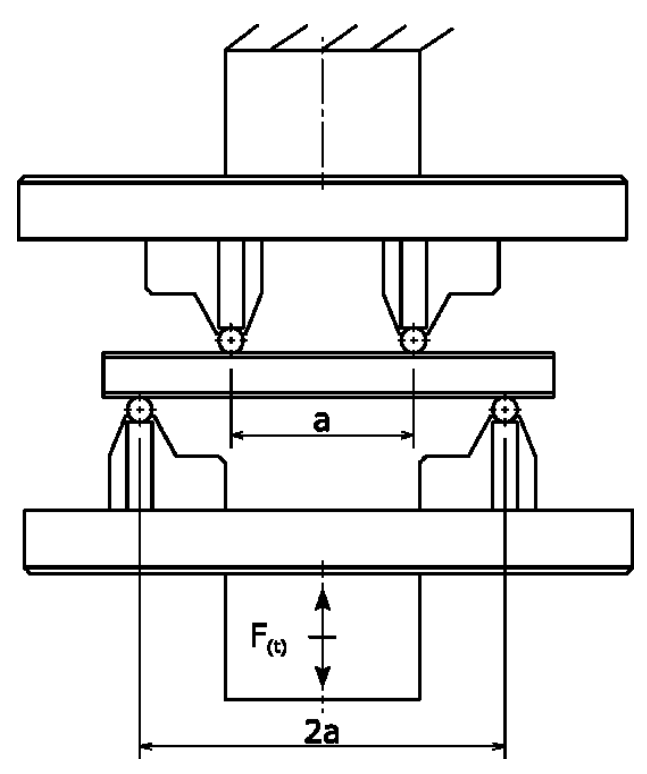

Fig. 5. Setup of a fatigue testing four-point bending

Cyclic testing of both type of specimens has been executed under force controlled loading mode. According to [6], a pulsating loading cycle has been chosen witch loading ratio $R=0,1$. The main characteristics of loading cycle are shown in Fig. 6(a).

Experimental specimens were loaded in the force control mode. Failure condition of the experimental specimens was defined by the moment of the so-called "technical initiation of a fatigue crack" (which, in case of our composite sandwich structure, can be considered as a crack in the length of 3-5 mm). The number of cycles prior to the initiation of the fatigue crack was determined on the basis of a continuous measurement of the deformation response to the loading regime of the test specimen $\mathrm{F}_{\mathrm{a}}=$ const. Completion of the test was defined either by the significant increase of the deformation in reference to the mean value or by the achievement of the life time of $10^{6}$ cycles. The loading frequency has been set up to $5 \mathrm{~Hz}$, thermo camera (Fig. 6(b)) has been used to ensure that specimen temperature has not increase more than $2^{\circ} \mathrm{C}$ as a result of inner heating under chosen loading condition.
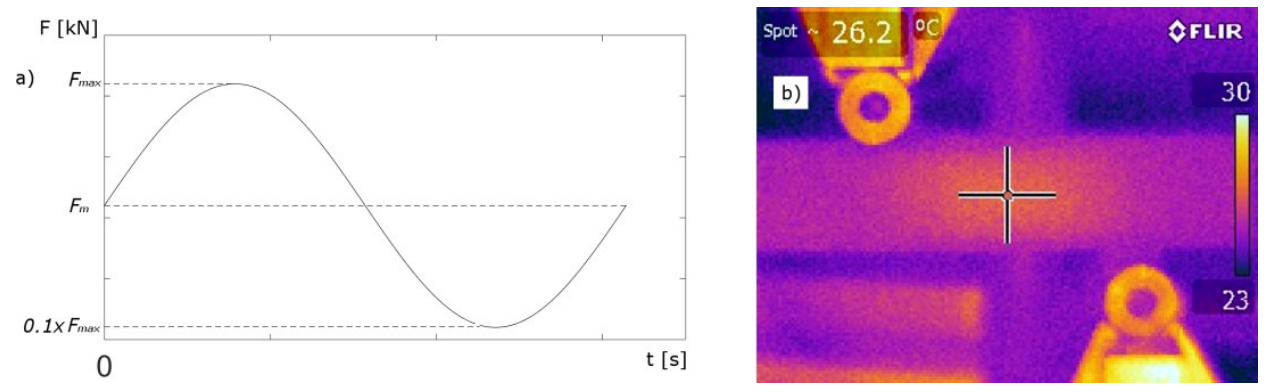

Fig. 6. (a) loading cycle description; (b) thermo camera measurement 


\section{Results and discussion}

Based on quasi-static, there was only one composition chosen to be tested regarding fatigue behaviour.

\subsection{Fatigue behaviour/properties}

\subsubsection{Fatigue curve}

Fatigue life time curves in a form of an exponential function were used to describe cyclic behavior of experimentally tested specimens. The exponential form has been chosen due to the fact that it is the most widely used form of fatigue curve [7, 8] which describes the fatigue behavior of various materials quite accurately. The final fatigue life time curve can then be defined as a relation between maximal force in one loading cycle $F_{n f}$ and a number of cycle repetitions until failure $N_{f}$. The curve is described by equation (1).

$$
F_{n f}=K\left(2 N_{f}\right)^{b}
$$

The $K$ and $b$ can be called fatigue strength coefficient and fatigue strength exponent respectively. They represent material characteristics of tested specimens and have to be obtained statistically from measured data. The $N_{f}$ is commonly multiplied by two in this type of function, as $K$ then represents theoretical static ultimate force. The measured data are in table 1 . The parameters $K$ and $b$ for regress line as well as for $95 \%$ upper and lower confidence and predictive intervals are in Table 2.

Table 1. Experimental data

\begin{tabular}{|c|c|c|c|c|c|c|c|}
\hline MON. & \% $_{\mathbf{F u}}[\%]$ & $\mathbf{F}_{\mathbf{n f}}[\mathrm{kN}]$ & $\mathbf{N f}[$ cycles] & INSERT & \% $_{\mathbf{F u}}[\%]$ & $\mathbf{F}_{\mathbf{n f}}[\mathrm{kN}]$ & $\mathbf{N f}[\mathrm{cycles}]$ \\
\hline MO-09-85 & 85 & 4.21 & 32584 & $\mathrm{I} 50-02-85$ & 85 & 4.59 & 5078 \\
\hline MO-03-75 & 75 & 3.71 & 390638 & $\mathrm{I} 50-01-80$ & 80 & 4.32 & 15500 \\
\hline MO-08-75 & 75 & 3.71 & $1000000 *$ & $\mathrm{I} 50-03-75$ & 75 & 4.05 & 195376 \\
\hline MO-02-70 & 70 & 3.47 & 462935 & $\mathrm{I} 50-07-75$ & 75 & 4.05 & 544046 \\
\hline MO-07-68 & 68 & 3.37 & $1000000 *$ & I50-04-70 & 70 & 3.78 & 769041 \\
\hline MO-06-65 & 65 & 3.22 & $1116473^{*}$ & I50-05-65 & 65 & 3.51 & $1000000^{*}$ \\
\hline MO-05-58 & 58 & 2.87 & 677425 & I50-06-58 & 58 & 3.13 & $1000000^{*}$ \\
\hline MO-04-58 & 58 & 2.87 & $1000000^{*}$ & - & - & - & - \\
\hline MO-01-40 & 40 & 1.98 & $1599973 *$ & - & - & - & - \\
\hline
\end{tabular}

The fatigue life time curves for monolith and insert specimens can be seen in Fig 7. Instead of maximum force per cycle, the fraction of ultimate force in percentage (formula (2)) has been used for Y axis. In this form, the fatigue curves can be easily compared to each other.

$$
\%_{u f}=\frac{F_{n f}}{F_{u}} 100
$$


Table 2. Parameters of fatigue curves

\begin{tabular}{|c|c|c|c|c|c|}
\hline \multicolumn{3}{|c|}{ MONOLITH } & \multicolumn{3}{c|}{ INSERT } \\
\hline- & $\mathbf{K}[\mathrm{kN}]$ & $\mathbf{b}[-]$ & - & $\mathbf{K}[\mathrm{kN}]$ & $\mathbf{b}[-]$ \\
\hline RL & 7.27 & -0.0025 & RL & 8.86 & -0.0032 \\
\hline UPI & 7.41 & -0.0025 & UPI & 9.26 & -0.0032 \\
\hline LPI & 7.13 & -0.0025 & LPI & 8.48 & -0.0032 \\
\hline UCI & 7.79 & -0.0025 & UCI & 12.6 & -0.0039 \\
\hline LCI & 6.77 & -0.0026 & LCI & 6.95 & -0.0027 \\
\hline
\end{tabular}

a)

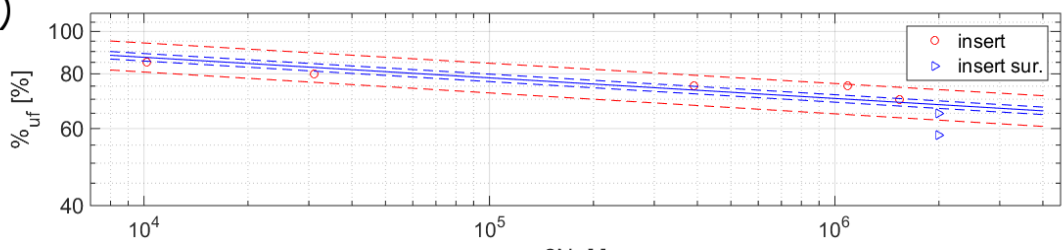

b)

$2 \mathrm{~N}_{\mathrm{f}}[-]$

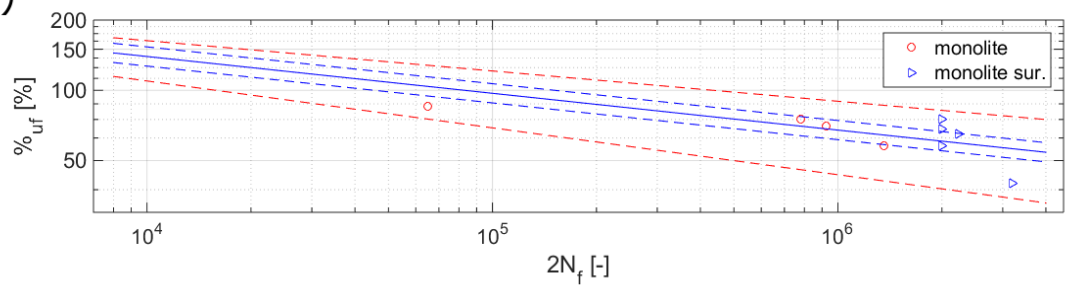

Fig. 7. (a) Insert fatigue curve; (b) monolith fatigue curve
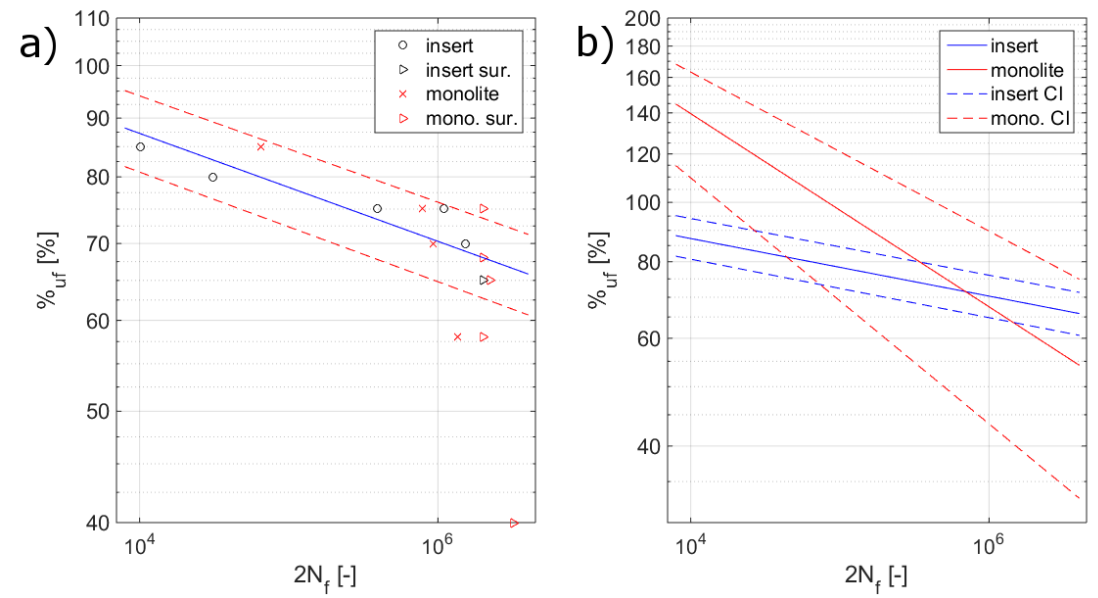

Fig. 8. (a) Insert curve with monolith points; (b) comparison of insert and monolith fatigue curve

During the experiment, we have found out that some of monolith specimens tend to fail after relatively small number of cycles (after tens or hundreds cycles) even under low loading levels. These fails were not caused by fatigue damage accumulation, but rather by 
manufacturing defects of adhesive film between foam and shell. As a result of this, the fatigue life curve for monolith specimens has much wider confidence interval and curve has significantly different slope than fatigue curve of insert specimens as can be seen in Fig. 8(b).

\subsubsection{Cyclic ratcheting}

Alongside fatigue life time curves, other useful information can be obtained from fatigue testing. Cyclic ratcheting describes behaviour of materials under non-symmetrical loading condition. Due to the fact that in real operation the loading cycles are rarely symmetrical, it is very useful to have a knowledge of how sensitive material is under non-symmetrical loading conditions. This sensitivity can be described by cyclic ratcheting curves which show increase of static (mean) flexure during life time. The ratcheting curves for monolith and insert specimens are shown in Fig. 9.
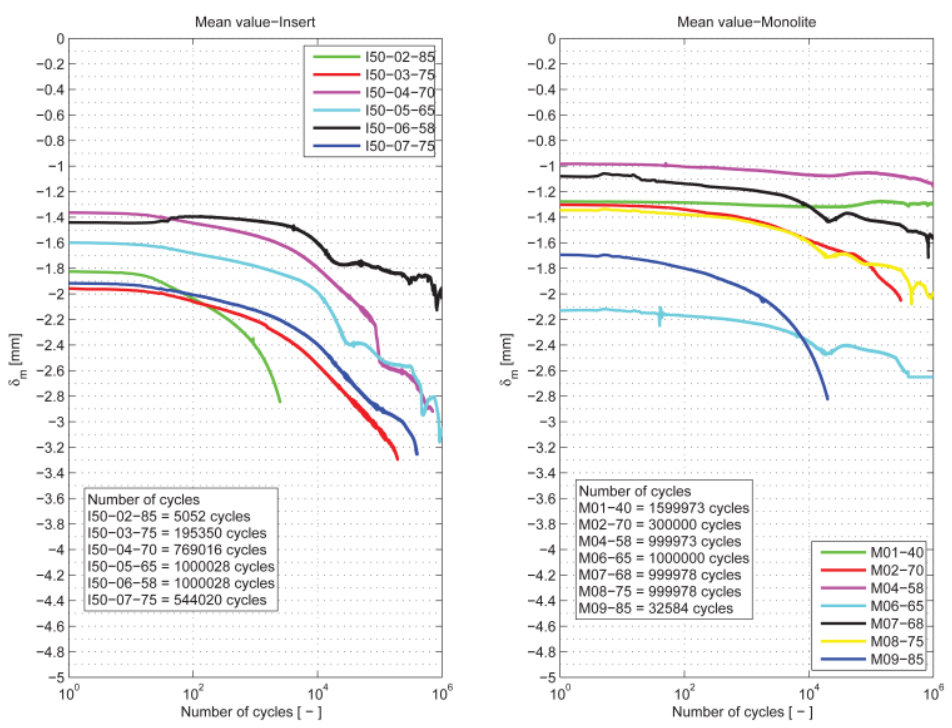

Fig. 9. Insert (left) and monolith (right) ratcheting curves

As can be seen in Fig. 9, the mean value of flexure is relatively stable during the first several cycles, and then starts to increase slowly, up to rapid increase in the last stage of life time. The small fluctuations in curves are caused by the error of a displacement sensor.

During the testing, it was observed that static flexure of tested specimens has disappeared after specimens had been unloaded. However, after several cycles of follow-up loading, it has come back into the state before unloading. Because of this, we can assume that the mean (static) flexure is caused by damage accumulation rather than a slow response of material to the variable loading condition. 


\subsubsection{Failure modes}

After investigation of tested specimens, two kinds of failure modes have been observed in both types of specimens. Both of these crack types occurred in region between upper and lower support.

In the first case, crack initiated in the boundary layer between skin and foam. Crack started to grow in the place under upper support where maximal combination of bending moment and transverse force exists. Crack then grew parallel to the skin shell in skin/foam boundary region. When crack size caused loss of flexure stiffness, foam failed in static crack under $45^{\circ}$ angle. This type of crack is shown in Fig. 10(a), the red arrow pointing to crack initiation region. The driven force of this crack is combination of normal stress caused by bending moment and shear stresses caused by transverse force and hertzian pressure from support.

In the second case, crack initiated in the middle of specimens' cross section in occurrence of maximal shear stress caused by transverse force Fig. 11. Crack then grew in direction of maximal shear stress planes $\left(0^{\circ}\right.$ or $90^{\circ}$ to specimens' cross section Fig. 10(c) and Fig. 10(b) respectively). When growing crack reached significant size, specimens lost flexure stiffness which caused foam fail in static crack under $45^{\circ}$ angle. This type of crack is shown in Fig. 10(b,c), the red arrow pointing to crack initiation region. The driven force in this cracking mode is shear stress caused by transverse force.

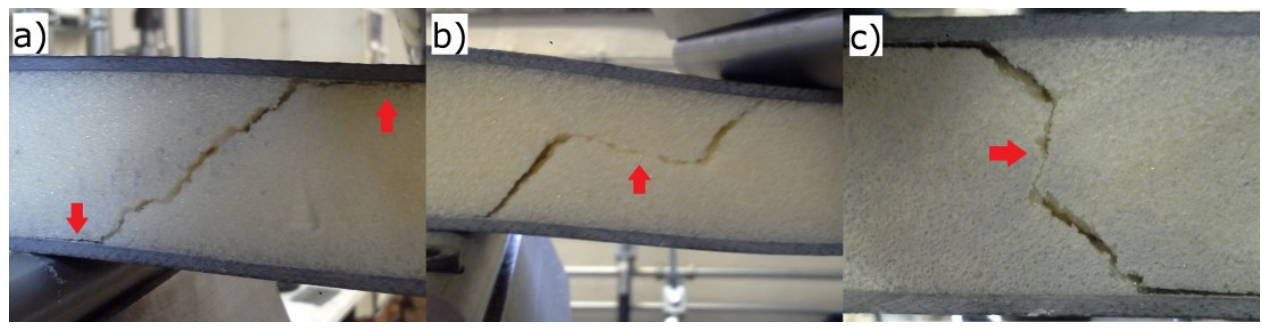

Fig. 10. Failure cracks: (a) skin/foam boundary region; (b) middle of cross section - parallel; (c) middle of cross section - perpendicular

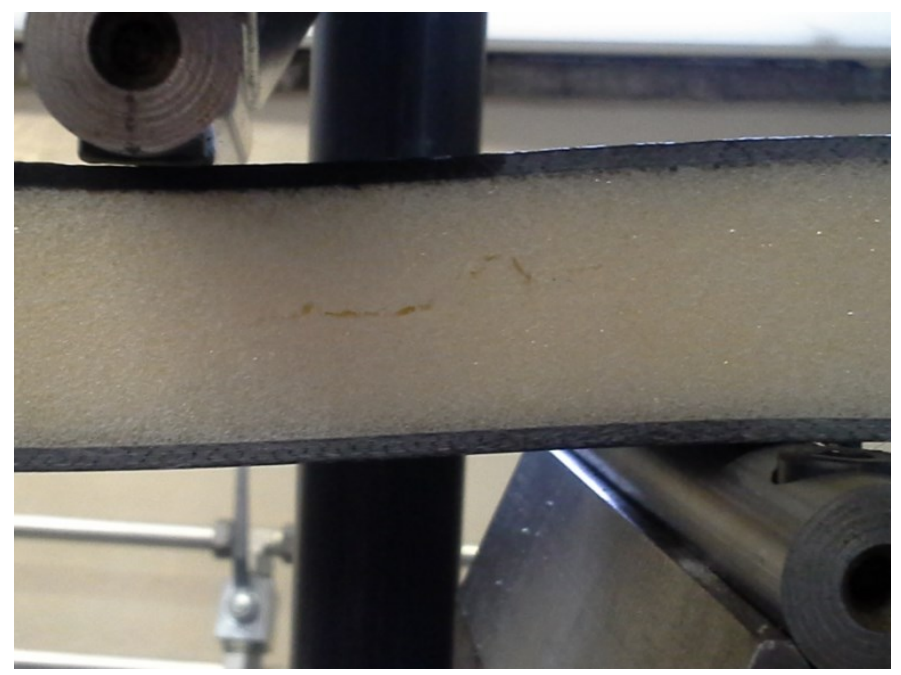

Fig. 11. Fatigue crack initiation and first stages of crack growth 


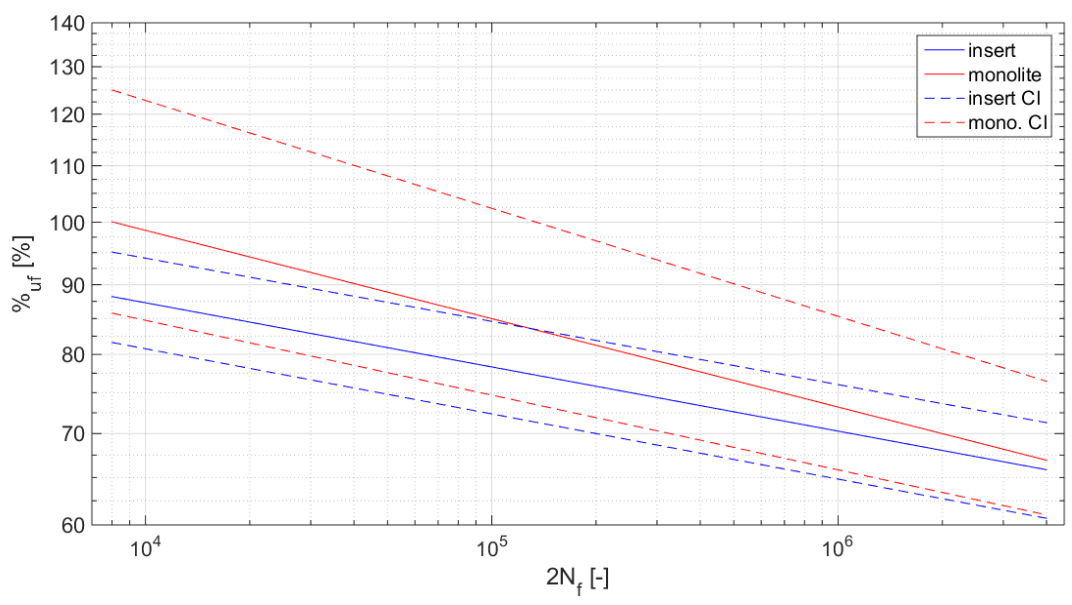

Fig. 12. Corrected comparison of fatigue curves for monolith and insert specimen

\section{Conclusion}

The investigation of sandwich composite structure under cyclic loading has been presented in this paper. Two types of sandwich specimens have been tested under four-point bending loading mode. Based on observations discussed in previous chapters, the following conclusions can be made:

- The driven force of fatigue damaging and fatigue crack initiation is the shear stress acting in foam part of a sandwich structure. Whether it is in the middle of cross section or in the boundary region between foam and foam/skin adhesive, fatigue crack initiates and grows in shear stress plane orientation till it reaches some critical length. Then the specimen cracks under $45^{\circ}$ angle to previous crack orientation.

- Cyclic ratcheting after several loading cycles has been observed for both specimen types and under various loading levels. Static (or mean) flexure slowly disappears after unloading, but after several followed up loading cycles comes back to levels before unloading.

- When comparing data points for both types of specimens in $\%_{\mathrm{uf}}-\mathrm{N}_{\mathrm{f}}$ coordinate system, it seems that both specimens types fatigue behavior could be described by the same fatigue curve (Fig. 8a)). The different slopes of fatigue curves can be ascribed to inconsistency of monolith specimens data. By excision of problematic monolith data point the corrected fatigue curve is much similar to insert curve. However this hypothesis should be prove on bigger data sets, because after excision of problematic monolith data points, the data aren't representative anymore.

This work was supported by the Slovak Research and Development Agency under Contracts-No. APVV-0015-12and was also supported by the Scientific Grant Agency under the Contract No. VEGA $1 / 0301 / 17$

This contribution has been elaborated under the bilateral project APVV SK-FR-2015-0016. 


\section{References}

1. G. Belingardi, P. Martella, L. Peroni, Fatigue analysis of honeycomb-composite sandwich beams. Composites Part A: Applied Science and Manufacturing 38 (4), 1183-1191, ISSN 1359-835X, (2007)

2. E. Bozhevolnaya, A. Lyckegaard, Structurally graded core inserts in sandwich panels. Composite Structures 68 (1), 23-29, ISSN 0263-8223, (2005)

3. M. Burman, D. Zenkert, Fatigue of foam core sandwich beams - 1: undamaged specimens. International Journal of Fatigue 19 (7), 551-561, ISSN 0142-1123, (1997)

4. A. C. Manalo, T. Aravinthan, W. Karunasena, M. M. Islam, Flexural behaviour of structural fibre composite sandwich beams in flatwise and edgewise positions. Composite Structures 92 (4), 984-995, ISSN 0263-8223, (2010)

5. H. Mathieson, A. Fam, High cycle fatigue under reversed bending of sandwich panels with GFRP skins and polyurethane foam core. Composite Structures 113, 31-39 (2014)

6. Plastiques renforcés de fibres - Détermination des propriétés de fatigue en conditions de chargement cycliques. Standard ISO 13003:2003 (F)

7. J. A. Bannantine, J. J. Comer, J. L., Handrock, Fundamentals of Metal Fatigue Analysis. (Prentice-Hall, New Jersey, 1990)

8. M. Klesnil, P. Lukas, Fatigue of Metallic Materials. (Elsevier Science, ISBN: 9780444987235, 1992) 